\title{
Developing Human and Organizational Factors in a Company
}

\section{Some Lessons from Ergonomics?}

\author{
François Daniellou
}

\begin{abstract}
The issue of the development of human and organizational factors of industrial safety in a company can be nourished by the experience gained from ergonomics. The author draws lessons from some French examples.
\end{abstract}

Keywords Ergonomics $\cdot$ Organizational design $\cdot$ Human factors

\section{Introduction}

"If we want to develop human and organizational factors in the company, how should we organize it?" This is basically the question that industrial groups have asked FonCSI to examine in this strategic analysis. The issue relates, of course, to the consideration of human and organizational factors of industrial safety. My past career as an ergonomics teacher leads me to suggest that it could usefully be nourished by an understanding of the successes and failures of the development of ergonomics in French companies.

The relationship between the terms human and organizational factors and ergonomics is unclear. For the International Ergonomics Association, human factors and ergonomics are simply synonyms, and are covered by the same definition:

Ergonomics (or human factors) is the scientific discipline concerned with the understanding of interactions among humans and other elements of a system, and the profession that applies theory, principles, data and methods to design in order to optimize human well-being and overall system performance.

In the field of industrial safety, the terms human factors (HF) or human and organizational factors (HOF) have a wider scope: they refer to the multidisciplinary study of the conditions that foster an efficient and safe human activity, and they encompass the contribution of all individual and collective human sciences.

\footnotetext{
F. Daniellou ( $\varangle)$

FonCSI, Toulouse, France

e-mail: francois.daniellou@foncsi.icsi-eu.org

(C) The Author(s) 2020

B. Journé et al. (eds.), Human and Organisational Factors,

SpringerBriefs in Safety Management,

https://doi.org/10.1007/978-3-030-25639-5_6
} 
The trend is towards a reconciliation of these two approaches: organizational dimensions are becoming more and more a concern for ergonomists, due to the development of interventions in design phases on the one hand, and to the prevention of musculoskeletal disorders and psychosocial risks on the other.

\section{Some Industrial Examples}

In France, the first industrial ergonomics lab was created in 1955 at Renault by Wisner [2]. While its founder wanted to address the ergonomics of plants as much as that of cars, the senior management did not permit it. Their main concern was to design cars that allowed the largest number of people to drive (and therefore buy) them. Only much later did ergonomists and "sociotechnical engineers" participate in the design of assembly lines: the concern was then to maintain in employment a large population of workers aged over 40 .

In the field of chemistry, Rhône-Poulenc played a pioneering role in the 1980s with the design of control rooms. After difficulties encountered at the start of several industrial projects, Jacques Laplace (a Human Resource manager), Denis Regnaud (a socio-technician) and Michel Guy (an ergonomist) formalized a systematic participatory HOF approach to design projects, including the early assignment of future operational teams, and their association with the project in the frame of an "Operational Project Team" [1]. Regrettably, after several years of success, investments in France dried up and the approach was discontinued.

In the aircraft industry, at Aerospatiale, a double development took place: on the one hand, a strong contribution of ergonomists to the industrial design of assembly lines emerged in the late 1980s; on the other hand, there was a notable development in the human factors of cockpit design after the Mont Saint-Odile accident (due to regulatory pressures and thanks to several internal and external sponsors). Those two dynamics have been perpetuated and are currently converging (see Florence Reuzeau's chapter in this book).

Assistance Publique Hôpitaux de Paris, ${ }^{1}$ in the late 1980 s, made the presence of ergonomists in the design of new hospital units mandatory and created for this purpose a central ergonomics department, which has now disappeared.

At $\mathrm{EDF}^{2}$ the "ergonomics/HF" concern developed in several departments: in the occupational medicine department around occupational health, in the Nuclear Production Directorate for the issue of nuclear safety, particularly in the Engineering department for the design and modification of control rooms and procedures-drawing the lessons from Three Mile Island accident- in the R\&D department for nuclear safety, as well as for the usability of software and home automation.

This list of examples is, of course, non-exhaustive but may help us to try and draw some generalisable lessons.

\footnotetext{
${ }^{1}$ Which manages all public hospitals in Paris.

${ }^{2}$ The historical French electricity operator.
} 


\section{Some Success Factors}

The emergence of "ergonomics/HF" departments always results from a combination of:

- a major threat for the company (industrial accident, repeated failure of investment projects, number of occupational diseases, low product attractivity...);

- the sustained involvement of internal individuals, educated in ergonomics, and of industrial decision makers who have been convinced by significant examples;

- in the case of energy and aeronautics, the role of regulatory bodies who pay attention to this focus and impose minimum standards.

The following factors of success may be identified.

\subsection{A Close Connection between Practitioners and Academics}

The development of French-speaking ergonomics has been marked by a strong connection between academic institutions and practitioners, including within SELF, the Société d'ergonomie de langue française. On the one hand, academics made important efforts to offer continuous education programmes for practitioners, allowing them to update their knowledge according to research developments. On the other hand, and most importantly, some labs have developed 'research on practice', starting from researchers' field interventions as well as from sustained interactions with internal or consultant practitioners. These exchanges allowed a common analysis of successes and difficulties, and the discussion of 'models' of interventions on various topics (in investment design projects, for the prevention of musculoskeletal disorders or psychosocial risks, etc.). Most ergonomists who were 'pioneers' in their company belonged to such academic networks.

\subsection{Leading by Example}

The story of the development of ergonomics in an organization often starts like this. Well before ergonomics/HF have an acknowledged status in the company, one or several individuals of relatively low rank, and/or an external consultant play an outstanding role in using HF methods to overcome a problem which the organization had, until then, been unable to resolve. Some such examples attract the attention of high-level decision makers, who firstly issue multiple requests, then advocate for an institutionalization of the approach. 


\subsection{Organization around Key Processes}

The most sustainable examples are those where the ergonomics/HF approach is structured around the company's key processes.

Let us take the example of the PSA group, which employ several dozen ergonomists. Some of them contribute to vehicle design (increasingly so, due to the digitalization of driving). Others are assigned to the design of assembly lines and plant units (giving feedback on the car design to ensure its manufacturability), others to production plants. The last two groups have the same management team and ergonomists switch from one to the other.

The key processes- "product design", "design of production means", "operation"- -are the most common, but probably not the only ones. Ergonomics/HF are usually mobilized to ensure (together or separately) safe and easy use of the product, production quality and occupational health and safety. In some cases, the humans who are the targets of the action are customers or users, in some cases they are employees, sometimes both (the design of a car that be saleable and manufacturable).

Of course, those key processes will evolve, as will the respective weights of the stakeholders who embody them. Detecting these evolutions and adapting the response is a key element of a sustained contribution of ergonomics.

\subsection{Combining Ready-Made and Haute Couture}

The sponsors of the ergonomics/HF approach rapidly became aware that it was not possible to have an ergonomist standing behind each design engineer to ensure, as a minimum, compliance with anthropometric and perceptive standards. It was necessary to guarantee and assess the integration of basic ergonomic prescriptions from the very first drawings, without waiting for the project reviews which generate late, expensive and conflict-provoking modifications.

One of the first tools designed with this objective was the famous 'Renault grid', which allowed for an early scoring of work stations, and led to prohibiting those that entailed significant risks. Like other tools that have successfully followed this one, it presented the following features:

- good usability, requiring only a few hours of training;

- a transversal nature, which made it a boundary object between designers, production managers and HF specialists;

- a mandatory character, with the commitment not to produce work stations with extreme scores;

- periodic revision — albeit not too often — to integrate new risks and new knowledge. 
While being heavily criticized by the most purist external ergonomists for its 'simplistic' nature, this tool played a considerable role in the integration of an ergonomic 'minimum' throughout the whole group. It also freed up ergonomists for tailormade interventions where their skills were mobilized at a higher level. Haute couture becomes a de facto necessity for the design of an efficient and safe work organization.

Beyond the circulation of these historical standards, some companies today provide managers and project leaders with HF procedures and methods, e.g. for analysing adverse events, anticipating the socio-organizational consequences of a change, etc. These approaches are the object of training programmes and an accompaniment by HF specialists.

\subsection{Associating Health and Performance}

If interest in occupational health and safety is real in some companies, for human and/or financial reasons, it is seldom enough of a concern to ensure the allocation of the resources needed for the structuration of ergonomics/HF in the organization.

The demonstration of the contribution of human work to the organization's global performance is always necessary, if this approach is to be implemented. It can be based on different statements: quality improvement (decrease of defects and scrap), increased flexibility of production, improvement in the operation rate of machinery, reduction in absenteeism and employee turnover, winning demanding clients, prevention of major industrial risks.

\subsection{Micro and Organization Levels}

One of the main features of the ergonomics/HF approach is to constantly connect the "microscopic" understanding of activity in the workplace with organizational or strategic dimensions. Many ergonomists have in the last 20 years followed a route that led to influence higher order determinants, those connected to work and company organizations. This attempt proves more successful when their intervention occurs at the early stages of technical or organizational design rather than in curative actions.

\subsection{The Central/Decentralized Mix}

In many cases, the structuration of the ergonomics/HF approach combines:

- specialists who are seconded close to the operational trades and sites, whose actors and processes they know in depth; 
- a light-handed central team, which defines generalisable processes and fosters the sharing and capitalization of experiences. They also act as a two-way relay with the top management.

This structure is similar to the one that can be found in HSE departments in many cases.

\subsection{Some Specialists and a Network}

Whatever their number and competence, ergonomists alone cannot detect and influence all processes where a HF approach would be required. They must rely on a dual network:

- an internal network of correspondents, interested managers and, in certain cases, personnel representatives, who have been trained and act as informants and relays with the trades;

- an external network of trusted consultants, to whom some of the interventions may be subcontracted, and with whom a joint elaboration of generalizable lessons is possible.

\subsection{A Solid and Discreet Theory}

In countries inspired by 'activity ergonomics', training in ergonomics emphasises the gap between prescribed work and real work, the constant adaptation of the worker's operating strategies to cope with the variability of the work situation and his/her own variability, the importance of the vitality of the work group, the physiological, cognitive and psychological strain related to various tasks, etc. The curricula also provide classic intervention methods that may be adapted to each specific situation. The theoretical background of the ergonomist's intervention is a solid one and is regularly discussed and updated in professional meetings.

Nonetheless, the ergonomists' professional success relies mostly on their capacity to speak their partners' language rather than that of their professors and on their ability to introduce the HF approach as naturally as possible in existing structures and processes.

This dialogue requires the sharing of some HOF knowledge and practice with counterparts, through training programmes which allow them to discover how this approach may enlighten some of the issues they have to deal with and enhance their own professional practice. 


\section{Avenues for Progress}

Although, in some companies, the HOF approach seems solidly anchored, major difficulties relate to:

(1) the sustainability of actions which have been launched by confident managers, and may be under threat when they leave;

(2) the interface between the different departments in charge of the domain.

(1) To address this vulnerability, it is necessary to anchor practices that become inescapable in the organization as a consequence of their broad dissemination and their acknowledged contribution.

(2) Taking the human contribution into account in design and organizational decisions is a multifaceted issue: it includes product usability, attractivity and safety; operability of industrial facilities, ergonomics of work stations; organization of R\&D programmes; operational excellence, lean production; industrial safety, occupational health and safety; incentive and sanction policies, company's attractiveness, skills and age management, induction programmes and career management; social dialogue, participation, profit-sharing; industrial subcontracting policy...

In a major group, these issues are supported by different departments, that may carry distinct models of the human and of the organization. These organizational silos may be a source of contradictions. A well-known hospital example is the contradiction between wearing gloves, which is prescribed by the occupational health department to protect caregivers, and washing hands, which is recommended by the patient safety department to prevent nosocomial infections.

Individual contact between specialists from these different worlds usually exists, of course. What is at stake today is a shared (and therefore debated) vision of the conditions of human work that is efficient, safe, favourable to personal development, and a deep understanding of its contribution to the company's global performance.

If the horizon of such a generalization may seem distant, two dynamics may contribute to bringing it closer:

- Serious HOF educational programmes for managers and personnel representatives (at the university level as well as in the company) that help to overcome such clichés as "if all procedures were followed, there would be no problem" or "what you can't measure doesn't exist", and make it possible to establish minimal HOF steps in the processes;

- Multiple interactions between Human Resources, engineering departments, production, HOF and health specialists, in a context of technical and organizational design projects implemented with the strong participation of operation managers, employees and personnel representatives. 
What is eventually at stake is less the structuring of a HOF department than 'HOFizing the organization', ${ }^{3}$ or in other words, impregnating it with concern for the conditions of efficient and safe human work.

\section{References}

1. J. Laplace, D. Regnaud, Démarche participative et investissement technique: la méthodologie de Rhône-Poulenc, in Cahiers techniques UIMM, vol. 52 (UIMM, Paris, 1986)

2. A. Wisner, Quand voyagent les usines (Syros, Paris, 1985)

Open Access This chapter is licensed under the terms of the Creative Commons Attribution 4.0 International License (http://creativecommons.org/licenses/by/4.0/), which permits use, sharing, adaptation, distribution and reproduction in any medium or format, as long as you give appropriate credit to the original author(s) and the source, provide a link to the Creative Commons license and indicate if changes were made.

The images or other third party material in this chapter are included in the chapter's Creative Commons license, unless indicated otherwise in a credit line to the material. If material is not included in the chapter's Creative Commons license and your intended use is not permitted by statutory regulation or exceeds the permitted use, you will need to obtain permission directly from the copyright holder.

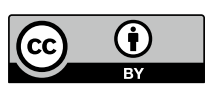

\footnotetext{
${ }^{3}$ According to Hervé Laroche.
} 